\title{
CONCENTRAÇÃO DE METAIS PESADOS NOS SEDIMENTOS DE CORRENTE NO PARQUE ESTADUAL DO ITACOLOMI E ARREDORES, MG.
}

\author{
Mara Regina de Oliveira (*), Hubert Mathias Peter Roeser (**) \& Adolf Heinrich Horn (***)
}

\begin{abstract}
Resumo
Este trabalho teve como objetivo, a investigação das concentrações de metais pesados selecionados em sedimentos de fundo em riachos do Parque Estadual Itacolomi e arredores na região de Ouro Preto, Minas Gerais. A água destes riachos é largamente utilizada pela população ribeirinha, levando estas pessoas a uma situação de vulnerabilidade a qualquer alteração da água. Foram investigados os elementos $\mathrm{Cd}, \mathrm{Cr}, \mathrm{Cu}, \mathrm{Ni}, \mathrm{Pb}$ e $\mathrm{Zn}$. As amostras foram coletadas seguindo a metodologia proposta pela CETESB (1988) e analisadas em um aparelho de espectrometria de emissão atômica do Laboratório de Geoquímica Ambiental do Departamento de Geologia da Universidade Federal de Ouro Preto, M.G. Os resultados mostram que os principais carreadores dos elementos traços nos sedimentos são material orgânico, minerais argilosos e oxidos e hidroxidos de Al, Fe e Mn. Para se avaliar a existência de valores anômalos de metais traços no sedimento de corrente na área, recorreu-se ao método do cálculo do fator de contaminação (F.C.) de cada elemento analisado. Os resultados demonstram que o cádmio tem concentração alta em alguns pontos da área de estudo, caracterizando alguns locais com concentrações anômalas deste elemento, não podendo se afirmar que se trata de intervenção antrópica. Os outros metais apresentam baixo fator de contaminação, caracterizando a área em estudo como não anômala para estes metais e suas principais fontes, são as rochas quartzíticas da Formação Cercadinho e do Grupo Itacolomi e dos xistos do Grupo Sabará.
\end{abstract}

\begin{abstract}
The aim of this work was to investigate the concentration of selected heavy metals in sediments of the bottom of rivers in Itacolomi State Park and surroundings, near the city of Ouro Preto, Minas Gerais. The water of these rivers and streams is widely used by riverside populations, which let these people vulnerable to water quality alterations. The water of these rivers is important for the provisioning of the population and therefore sensitive to any contamination. The elements $\mathrm{Cd}, \mathrm{Cr}, \mathrm{As}, \mathrm{Ni}, \mathrm{Pb}$ and $\mathrm{Zn}$ were investigated. The samples were collected following international standard procedures and analyses were done by optical atomic emission spectroscopy in the Laboratório Geoquímica Ambiental/ Universidade Federal de Ouro Preto, Minas Gerais. The results show that the main carriers of the elements in the sediments are organic material, clay minerals and oxides and hydroxides of $\mathrm{Al}, \mathrm{Fe}$ and $\mathrm{Mn}$.

To evaluate abnormal values of trace metals in current water sediments on the area, we used the calculus of contamination factor method for each element studied. Results show that $\mathrm{Cd}$ has high concentrations in some points of the studied area, characterizing some places with abnormal concentrations of this element, but it can not be assured that this is caused by antropic action. Other metals shows low contamination factor, characterizing the studied area as not abnormal for these metals, and their main sources are quartzical rocks of Cercadinho formation, Itacolomi Group, and Group Sabará schists.
\end{abstract}

\section{INTRODUÇÃo}

O Parque Estadual do Itacolomi está localizado entre os Municípios de Ouro Preto e Mariana, Minas Gerais (figura 1),com uma área de $70 \mathrm{~km}^{2}$, abrangendo toda a Serra do Itacolomi ou Serra Geral, uma das componentes da Cadeia do Espinhaço.
A área do parque tem em seu entorno atividades como extrações minerais, principalmente de minérios de ferro, manganês, ouro e pedras preciosas. Estas atividades geram alguns impactos ambientais. Por exemplo, numa mineração de ferro, o maior problema ambiental se refere ao produto de beneficiamento do minério, a lama residual que é descartada para a barragem. 


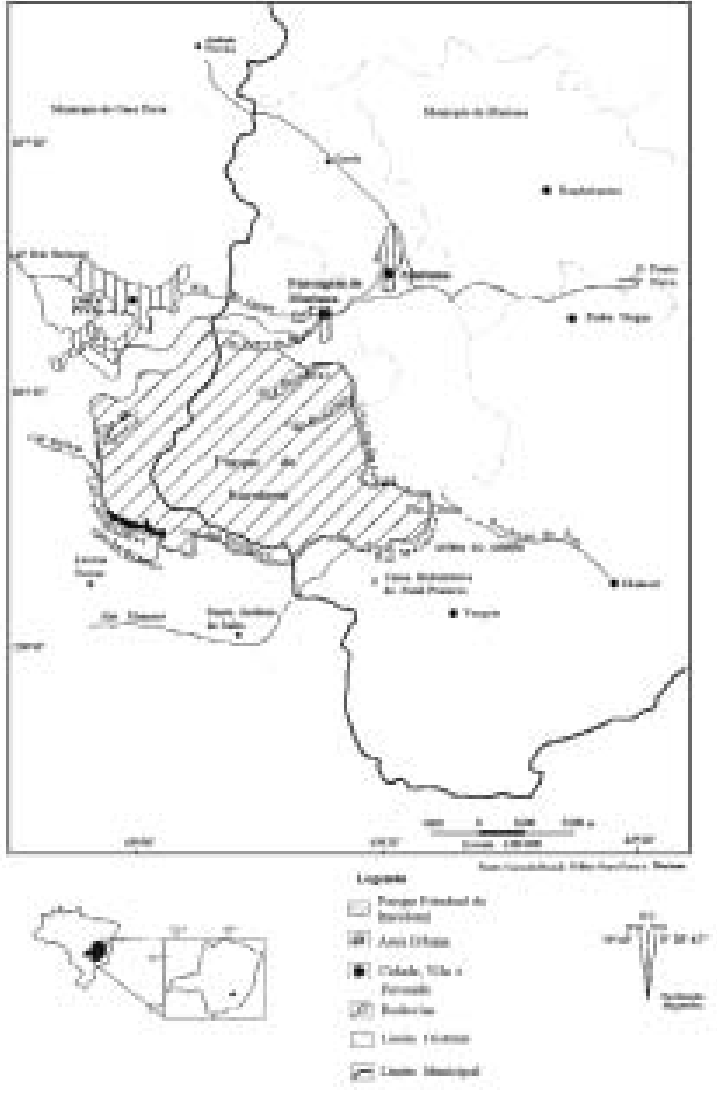

Figura 1: Mapa de localização da área da pesquisa(DNPM/CPRM 1993; modificado)

Como na área de estudo não existem evidências de atividades antrópicas atuais, é importante que as características das águas dos rios que atravessam toda a extensão do parque sejam analisadas, a fim de se obter valores de níveis de base, ou seja, o background deste ambiente para determinados elementos, e que sirvam de referência para estudos posteriores referentes ao impacto ambiental que venham a ser realizados a jusante desta área.

Assim, este trabalho consiste no levantamento das concentrações de metais pesados e do lítio no sedimento de corrente do Parque Estadual do Itacolomi e seus arredores e correlação com dados geoquímicos pré-existentes, dos tipos litológicos presentes na área. Além de uma análise crítica das condições ambientais destas águas.

\section{OBJETIVOS}

O objetivo deste trabalho é a determinação das concentrações de metais pesados como $\mathrm{Cr}, \mathrm{Co}, \mathrm{Ni}, \mathrm{Cu}, \mathrm{Zn}, \mathrm{Cd}$ $\mathrm{e} \mathrm{Pb}$ nos sedimentos de fundo/corrente dos riachos do Parque Estadual do Itacolomi e seus arredores, o nível de suas concentrações e como estes teores estão variando de montante para jusante nestes rios, correlacionando-as com as frações granulométricas, com o carbono orgânico e com a composição mineralógica dos sedimentos. E por fim comparálos aos dados de referências bibliográficas locais e de outras áreas, para se obter o background destes metais no compartimento investigado e fazer uma análise crítica das condições ambientais da área.

\section{GEOLOGIADA PORÇÃO OCIDENTALDASUB- BACIA DO RIO DO CARMO}

Nesta área ocorrem rochas do Complexo Santo Antônio do Pirapetinga e rochas supracrustais dos Supergrupos Rio das Velhas e Minas, como também do Grupo Itacolomi que contribuem com minerais que podem produzir anomalias de $\mathrm{Zn}, \mathrm{Au}, \mathrm{Cu}$. As áreas denominadas X, XI, XII, XIII, XIV e XV indicam anomalias ligadas a geologia(figura 2). Porém estas anomalias estão todas a jusante da área de estudo, indicando como áreas fontes, porções localizadas em cursos superiores dos córregos.

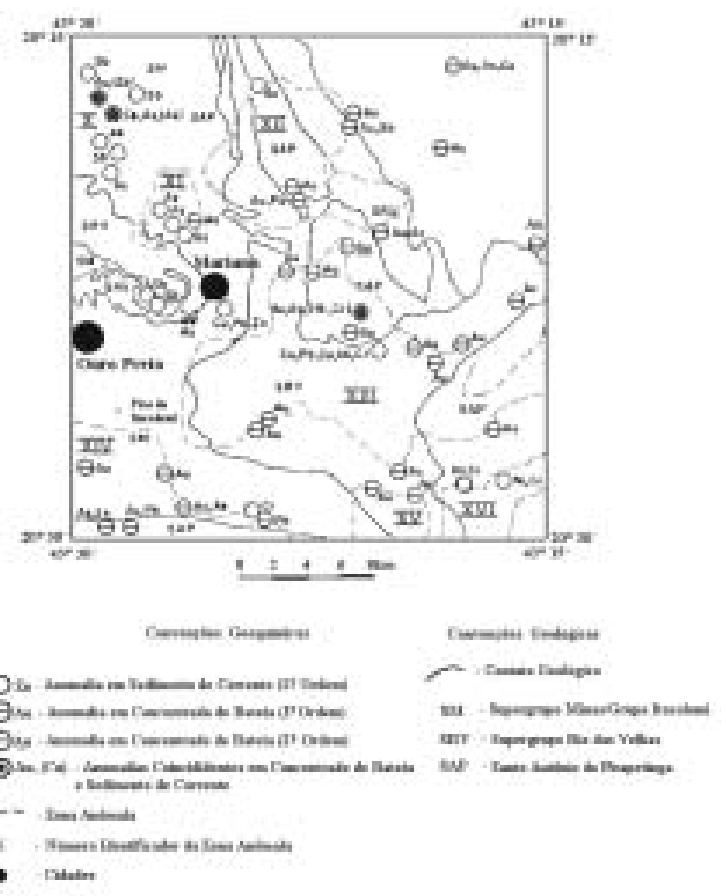

Figura 2: Mapa de anomalias geoquímicas na região(Souza \& Souza, 1993; DNPM 1993;modificado)

Os rios investigados neste estudo atravessam rochas da Formação Cercadinho e Grupos Sabará e Itacolomi. A formação Cercadinho do Grupo Piracicaba é constituída por quartzitos ferruginosos, quartzitos com cianita, filitos prateados e sericita xistos. O Grupo Sabará tem rocha predominante do tio clorita-xisto, com intercalações de quartzito e grauvaca com uma matriz composta por sericita, clorita, epídoto, rutilo e turmalina e alguns grãos maiores de quartzo e fragmentos líticos formados por quartzito.

OGrupo Itacolomi é uma unidade é definida como um quartzito que repousa com discordância angular sobre os metassedimentos anteriores. Dorr (1969) dividiu o Grupo Itacolomi em fácies Santo Antônio (filítica) e a Itacolomi (quartzítica).

OLevantamento Geoquímico do DNPM/CPRM(1993), na Folha Mariana que permitiram reunir unidades litológicas de acordo com a concentração dos elementos 
presentes em cada tipo litológico, reunir as rochas da área do parque e seu entorno em um grupo composto por unidades quartzíticas dos Supergrupos Rio das Velhas e Minas (incluindo o Grupo Sabará) e do Grupo Itacolomi, onde observa-se a associação de $\mathrm{Cu}-\mathrm{Pb}-\mathrm{Zn}$ $\mathrm{Co}-\mathrm{Ni}-\mathrm{Cr}$ podendo sugerir um enriquecimento secundário de óxidos e hidróxidos de ferro e a fonte de ferro seria a decomposição da formação ferrífera do Grupo Itabira.

O parque está localizado na sub-bacia do Rio do Carmo, pertencente à bacia hidrográfica do rio Doce. A rede hidrográfica do parque é definida pelo rio Mainart (que posteriormente encontra-se com o rio do Carmo na direção leste) e o ribeirão Belchior, que juntos formam o limite do parque, além de vários outros córregos afluentes destes, que muitas vezes têm suas nascentes muitas vezes no próprio parque. O sistema de drenagem é bastante variável, com predomínio dos padrões dentrítico e dentrítico-retangular, e os cursos d'água correm segundo a direção das camadas. A maioria dos córregos no parque possui águas cristalinas com $\mathrm{pH}$ variando de ácido a neutro, representado por uma variação de 4,5 em uma nascente nas proximidades do Pico do Itacolomi a 7,12 no rio Mainart, próximo a Santo Antônio do Salto.

\section{METODOLOGIA}

Para a análise dos metais pesados nos sedimentos de corrente foram coletadas amostras em 44 pontos, sendo 32 dentro do parque e 12 fora do parque(figura $3)$. As amostragens foram feitas no período chuvoso (outubro e dezembro de 1996 e janeiro, março e dezembro de 1997). Os locais de amostragem foram selecionados de modo a abranger toda a extensão do parque e escolhidos para caracterizar melhor a área, por exemplo, as confluências dos rios, nascentes e áreas de entorno do parque.

A coleta das amostras foi executada segundo normas da CETESB (1988).

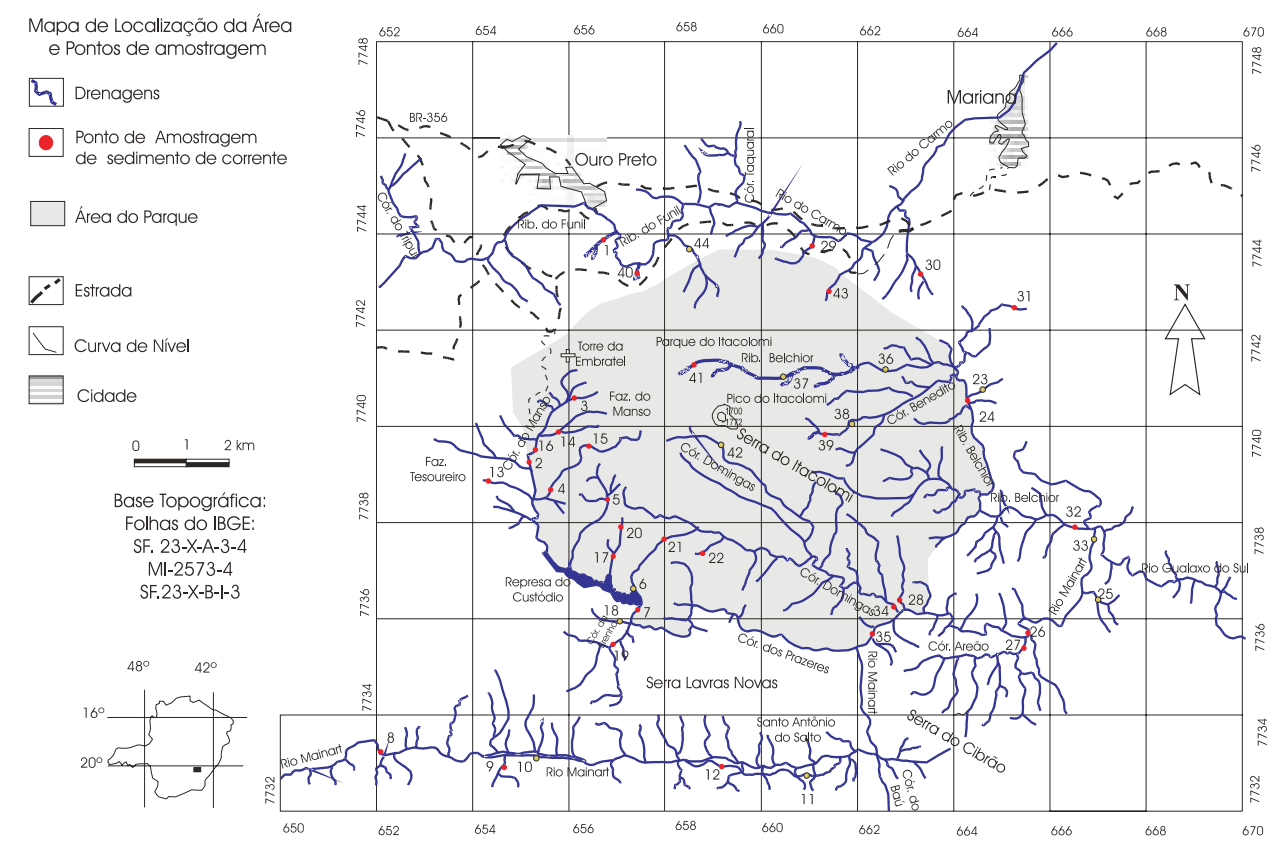

Figura 3: Mapa de localização de amostragem de sedimento de fundo nos riachos do Parque Estadual Itacolomi e arredores.

Geralmente as camadas superficiais dos sedimentos de fundo são as de interesse ambiental. A retirada de alguns centímetros deve ser feita a até aproximadamente $30 \mathrm{~cm}$ nas margens, evitando-se locais com águas estagnadas e também nas partes côncavas das curvas dos rios, pois nestes locais tendem a ocorrer as concentrações dos metais. Estas amostragens foram realizadas com uma pá plástica (figura 4). Coletou-se cerca de $2 \mathrm{~kg}$ de sedimento por amostra. Estas foram acondicionadas em sacos plásticos que foram previamente lavados com água deionizada. Ao se colocar amostras nestes sacos plásticos, esperou-se a decantação do sedimento e separação da água. Esta água foi descartada sem a perda de material sólido.

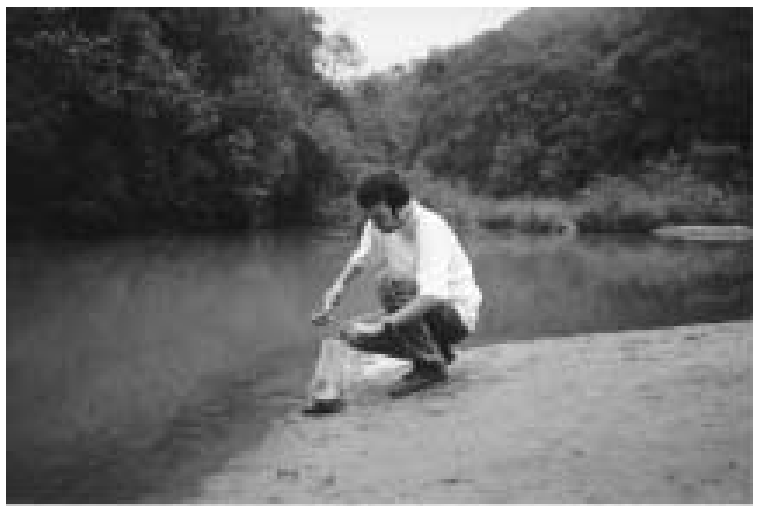

Figura 4: Método de coleta do sedimento de corrente utilizando uma pá de plástico. A amostragem foi realizada no rio Mainart, em dezembro de 1997 
Após serem secas à temperatura ambiente em sala limpa e escura, elas foram fracionadas em peneiras de nylon durante 20 minutos. Foram separadas as frações granulométricas $<0,088 \mathrm{~mm}$, entre $0,088 \mathrm{~mm}$ e $0,149 \mathrm{~mm}$ e $>0,149 \mathrm{~mm}$, as mais adequadas para a determinação dos metais pesados (Roeser et. al., 1984). As amostras foram abertas com $\mathrm{HCl}(36 \% \mathrm{p} / \mathrm{p} \mathrm{d}=1,17 \mathrm{~g} / \mathrm{ml})$ e posteriormente diluídas com água destilada para uma solução de 100 $\mathrm{ml}$. A determinação ocorreu num espectrofotômetro de absorção atômica de chama, marca Varian, modelo AA475. Para a padronização utilisaram-se padrões Titrisol da Merck, diluindo-se a solução estoque (1000 $\mathrm{mg} / \mathrm{ml}$ ) para uma solução padrão intermediária e depois para a solução final de $10 \mathrm{mg} / \mathrm{ml}$, de acordo com as recomendações do manual da Titrisol-Merck.
Para obter o carbono orgânico, dez amostras foram selecionadas e tratadas com $\mathrm{HCl}$ 2:1 a frio,e a determinação executada num Determinador Leco, modelo e marca LECO SC 444, versão 3.0, segundo o manual de instruções de análises de carbono e enxofre (in Leco- Corporation, 1995).

A caracterização dos minerais da fração argila foi feita por difração de raios-X no método não orientado e orientado, segundo Brindley \& Brown (1980) e Eslinger \& Peaver (1988).A leitura das amostras foi feita através do difratômetro Rigaku, modelo D/Max-2B. Os resultados dos difratogramas foram tratados pelo programa Jade for Windows XRD Pattern Processingand Indentification version 3.0. Todos estes aparelhos pertencem ao Laboratório de Difração de Raio X do Degeo/Ufop.

Tabela 1: Condições de Operação do Aparelho de Absorção Atômica Modelo Varian AA475 e AA1275.

\begin{tabular}{|l|l|l|l|l|l|}
\hline Elemento & \multicolumn{1}{|c|}{$\lambda$} & $\begin{array}{c}\text { Abertura } \\
\text { da Fenda } \\
\text { (nm) }\end{array}$ & $\begin{array}{c}\text { Corrente } \\
\text { da Lampada } \\
\text { (mA) }\end{array}$ & $\begin{array}{c}\text { Oxidante/ } \\
\text { Combustivel }\end{array}$ & $\begin{array}{c}\text { Limite de } \\
\text { Deteç̧o } \\
\text { (ppm) }\end{array}$ \\
\hline $\mathrm{Cu}$ & 324,7 & 0,5 & 3,5 & Ar/acetileno & 11,004 \\
\hline $\mathrm{Cr}$ & 357,9 & 0,2 & 7,0 & Ar/acetileno & 25,165 \\
\hline $\mathrm{Ni}$ & 232,0 & 0,2 & 3,5 & Ar/acetileno & 28,938 \\
\hline $\mathrm{Bb}$ & 217,0 & 1,0 & 7,5 & Ar/acetileno & 13,384 \\
\hline $\mathrm{Cd}$ & 228,8 & 0,5 & 3,5 & Ar/acetileno & 5,254 \\
\hline $\mathrm{Zn}$ & 213,9 & 1,0 & 5,0 & Ar/acetileno & 6,437 \\
\hline $\mathrm{Co}$ & 240,7 & 0,2 & 7,0 & Ar/acetileno & 11,653 \\
\hline
\end{tabular}

Uma das técnicas usadas para quantificar a contaminação da área é através da determinação do fator de contaminação (FC).Para isto foi adotado o método utilizado por Laybauer (1995) e Eleutério (1997). Assim define-se um ponto de controle da área, representativo do contexto geológico e que apresente concentrações de metais similares ao background regional. O ponto escolhido está situado a várias seqüências estratigráficas da região, podendo receber contribuições litogênicas não só da seqüência dentro da qual está inserido, mas também das litologias adjacentes. Portanto neste contexto, o ponto de controle é caracterizado por um sedimento mais heterogêneo e mais representativo da área pesquisada.

Usando os valores do background para a área é possível calcular o FC da forma proposta por Tomlison et al (1980 in Laybauer, 1995), o qual é definido como a razão entre a concentração do sedimento do ponto amostrado e o background da região, ou seja, quantas vezes o metal analisado ultrapassa o nível de base da região (tabela 2).

Tabela 2: Background da concentração de metais nos sedimentos do ponto de controle e nível de base através do folhelho padrão (Turekian. 1961) e o background regional (DNPM.1993 in Eleutério. 1997).

\begin{tabular}{|c|c|c|c|c|c|c|c|c|}
\hline Referências & $\begin{array}{c}\mathrm{Cr} \\
\text { ppm }\end{array}$ & $\begin{array}{c}\mathrm{Co} \\
\mathrm{ppm}\end{array}$ & $\begin{array}{c}\mathrm{Ni} \\
\mathrm{ppm}\end{array}$ & $\begin{array}{c}\mathrm{Cu} \\
\mathrm{ppm}\end{array}$ & $\begin{array}{c}\mathrm{Zn} \\
\mathrm{ppm}\end{array}$ & $\begin{array}{c}\mathrm{Cd} \\
\mathrm{ppm}\end{array}$ & $\begin{array}{c}\mathrm{Pb} \\
\mathrm{ppm}\end{array}$ & $\begin{array}{c}\mathrm{Li} \\
\mathrm{ppm}\end{array}$ \\
\hline $\begin{array}{c}\text { Folhelho } \\
\text { Padrão }\end{array}$ & 90,0 & 19,0 & 68,0 & 45,0 & 95,0 & 0,30 & 20,0 & 66,0 \\
\hline Regional & 67,0 & 16,0 & 32,0 & 22,0 & 31,0 & - & 15,0 & - \\
\hline $\begin{array}{c}\text { Ponto de } \\
\text { Controle }\end{array}$ & 88,0 & 22,45 & 51,88 & 50,0 & 79,58 & 0,85 & 34,81 & 2,76 \\
\hline
\end{tabular}

\section{RESULTADOS DAS ANÁLISES}

As tabelas a seguir mostram os valores calculadosdos fatores de contaminação para os metais nas três frações granulométricas analisadas em 10 amostras selecionadas.

Como pode ser visto nas Tabelas 3,4 e 5 o elemento que apresenta maior fator de contaminação é o $\mathrm{Cd}$, com valores que variam de $1,0 \mathrm{ppm}$ a $25 \mathrm{ppm}$. Os locais com valores mais elevados são fora dos limites do parque, em pontos dos rios que as águas se apresentaram maisturvas e com maior quantidade de assoreamento. Os outros metais mostram valores que não contrastam muito. A figura 5 mostra o fator de contaminação aumenta na direção de oeste para leste, segundo a direção da amostragem. 
Tabela 3: Fator de contaminação dos metais na fração granulométrica >0,149mm.

\begin{tabular}{|c|l|l|l|l|l|l|l|}
\hline $\begin{array}{c}\text { Pontos } \\
\text { Amostrados }\end{array}$ & \multicolumn{1}{|c|}{$\mathrm{Cr}$} & $\mathrm{Co}$ & $\mathrm{Ni}$ & $\mathrm{Cu}$ & $\mathrm{Zn}$ & $\mathrm{Cd}$ & $\mathrm{Pb}$ \\
\hline 2 & 1,22 & 0,18 & 0,38 & 0,66 & 1,23 & 7,05 & 0,98 \\
\hline 6 & 0,15 & 0,09 & $\mathrm{ND}$ & 0,08 & 0,19 & 2,35 & 0,43 \\
\hline 10 & 1,29 & 1,29 & 1,23 & 0,42 & 0,49 & 14,12 & 0,55 \\
\hline 11 & 0,39 & 0,53 & 0,38 & 0,18 & 0,02 & 1,18 & 0,20 \\
\hline 18 & 0,14 & 0,09 & $\mathrm{ND}$ & $\mathrm{ND}$ & 0,18 & 3,53 & 0,06 \\
\hline 20 & 0,31 & $\mathrm{ND}$ & $\mathrm{ND}$ & 0,1 & 0,04 & 1,18 & 0,46 \\
\hline 23 & 1,37 & 1,25 & 0,71 & 0,88 & 0,61 & 24,71 & 1,87 \\
\hline 33 & 0,28 & 0,44 & 0,32 & 0,18 & 0,40 & 2,35 & 0,26 \\
\hline 34 & 0,23 & 0,22 & 0,15 & 0,08 & 0,11 & 3,53 & 0,17 \\
\hline 36 & 0,04 & 0,04 & ND & 0,32 & ND & 1,18 & 0,23 \\
\hline
\end{tabular}

Tabela 4: Fator de contaminação dos metais na fração granulométrica entre 0,088mm e 0,149mm.

\begin{tabular}{|c|l|l|l|l|l|l|c|}
\hline $\begin{array}{c}\text { Pontos } \\
\text { Amostrados }\end{array}$ & Cr & Co & Ni & Cu & Zn & Cd & Pb \\
\hline 2 & 1,06 & 0,18 & 0,35 & 0,56 & 0,41 & 5,88 & 0,83 \\
\hline 6 & 0,18 & 0,09 & 0,12 & 0,1 & 0,21 & 2,35 & 0,57 \\
\hline 10 & 0,61 & 0,36 & 0,33 & 0,1 & 0,09 & 5,88 & 0,20 \\
\hline 11 & 0,84 & 0,53 & 0,40 & 0,1 & 0,04 & 9,41 & 0,37 \\
\hline 18 & 0,20 & 0,13 & ND & ND & 0,01 & 4,71 & 0,03 \\
\hline 20 & 0,28 & ND & ND & 0,08 & ND & 1,18 & 0,52 \\
\hline 23 & 0,60 & 0,67 & 0,35 & 0,46 & 0,24 & 24,35 & 1,29 \\
\hline 33 & 0,53 & 0,40 & 0,33 & 0,12 & 0,13 & 8,23 & 1,87 \\
\hline 34 & 0,36 & 0,31 & 0,19 & 0,12 & ND & 3,53 & 0,60 \\
\hline 36 & 0,14 & 0,13 & ND & 0,34 & ND & 2,35 & 0,09 \\
\hline
\end{tabular}

Tabela 5: Fator de contaminação dos metais na fração granulométrica <0,088mm.

\begin{tabular}{|c|l|l|l|l|l|l|c|}
\hline $\begin{array}{c}\text { Pontos } \\
\text { Amostrados }\end{array}$ & \multicolumn{1}{|c|}{$\mathrm{Cr}$} & $\mathrm{Co}$ & $\mathrm{Ni}$ & $\mathrm{Cu}$ & $\mathrm{Zn}$ & $\mathrm{Cd}$ & $\mathrm{Pb}$ \\
\hline 2 & 1,22 & 0,18 & 0,38 & 0,66 & 1,23 & 7,05 & 0,98 \\
\hline 6 & 0,15 & 0,09 & ND & 0,08 & 0,19 & 2,35 & 0,43 \\
\hline 10 & 1,29 & 1,29 & 1,23 & 0,42 & 0,49 & 14,12 & 0,55 \\
\hline 11 & 0,39 & 0,53 & 0,38 & 0,18 & 0,02 & 1,18 & 0,20 \\
\hline 18 & 0,14 & 0,09 & ND & ND & 0,18 & 3,53 & 0,06 \\
\hline 20 & 0,31 & ND & ND & 0,1 & 0,04 & 1,18 & 0,46 \\
\hline 23 & 1,37 & 1,25 & 0,71 & 0,88 & 0,61 & 24,71 & 1,87 \\
\hline 33 & 0,28 & 0,44 & 0,32 & 0,18 & 0,40 & 2,35 & 0,26 \\
\hline 34 & 0,23 & 0,22 & 0,15 & 0,08 & 0,11 & 3,53 & 0,17 \\
\hline 36 & 0,04 & 0,04 & ND & 0,32 & ND & 1,18 & 0,23 \\
\hline
\end{tabular}




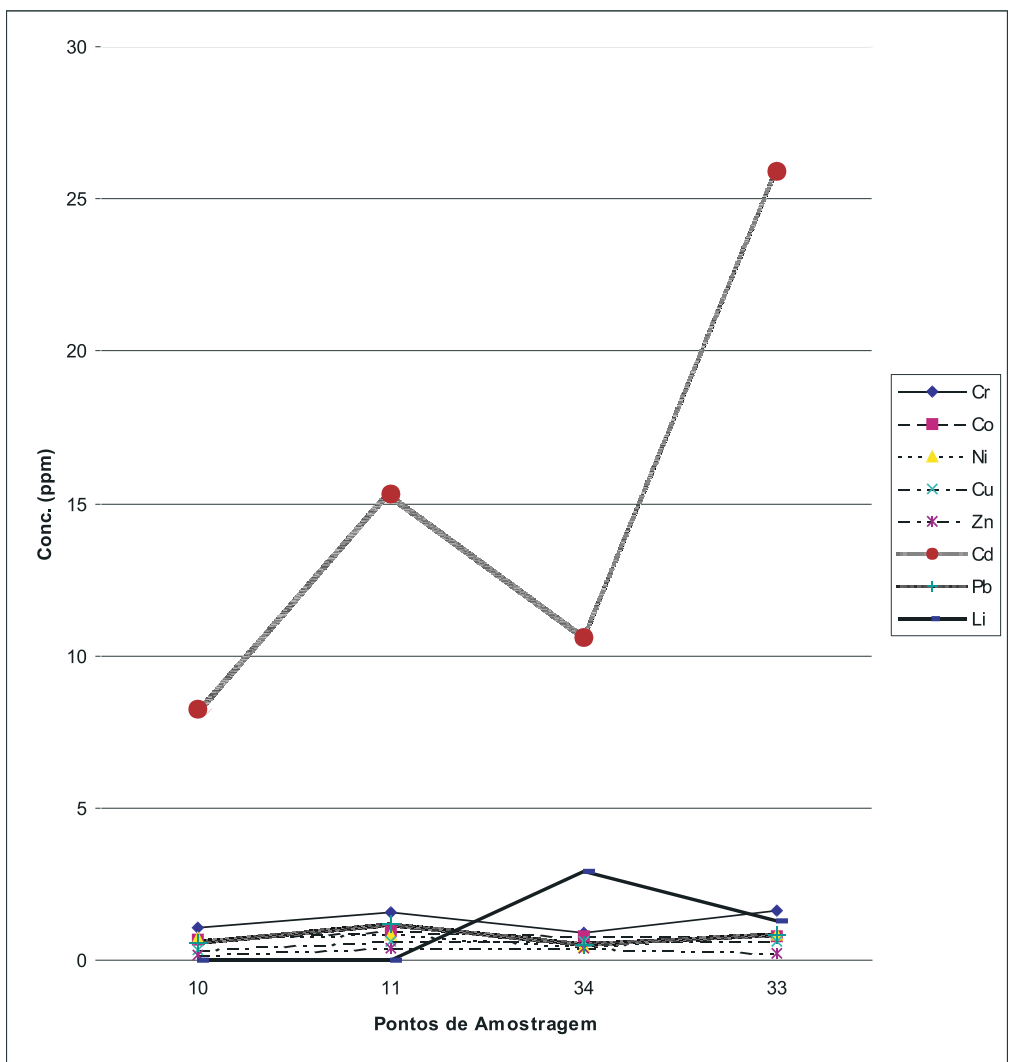

Figura 5: Fator de contaminação dos metais de oeste (MPI10) para leste (MPI33).

Em relação a mineralogia, observou-se que os sedimentos de corrente da área de estudo é composto principalmente pelos seguintes minerais: A composição mineralógica dos sedimentos da área em estudo é predominante de quartzo e em menor volume, de moscovita, goetita, clorita, ilita, antigorita $\mathrm{Mg}_{6}\left[(\mathrm{OH})_{8} / \mathrm{Si}_{4} \mathrm{O}_{10}\right]$, hematita e esmectita, comomostraa tabela 6 .

Tabela 6: A composição mineralógica das amostras investigadas.

\begin{tabular}{|c|c|}
\hline $\begin{array}{c}\text { Constituintes } \\
\text { Majoritărios }\end{array}$ & $\begin{array}{c}\text { Constituintes } \\
\text { Minoritărios }\end{array}$ \\
\hline Quartzo & Hematita \\
\hline Moscovita & Ilita \\
\hline Caulinita & Antigorita \\
\hline Goetita & Clorita \\
\hline & Biotita \\
\hline & Esmectita \\
\hline
\end{tabular}

A análise química e mineralógica das amostras da área em estudo nos mostra que os minerais encontrados podem ser fontes de $\mathrm{Fe}, \mathrm{Al}$ e $\mathrm{Mg}$. O Fe ocorre principalmente na forma de hematita $\left(\mathrm{Fe}_{2} \mathrm{O}_{3}\right)$, magnetita $\left(\mathrm{Fe}_{3} \mathrm{O}_{4}\right)$ e goethita $\left(\mathrm{FeO} . \mathrm{OH}_{\mathrm{n}_{\mathrm{n}}} \mathrm{H}_{2} \mathrm{O}\right)$. Outra fonte de ferro, porém em concentrações menores, é através da lixiviação da clorita $\left[(\mathrm{Mg}, \mathrm{Fe})_{3}(\mathrm{Si}, \mathrm{Al})_{4} \mathrm{O}_{10}\left(\mathrm{OH}_{2}\right)(\mathrm{Mg}, \mathrm{Fe})_{3}(\mathrm{OH})_{6}\right]$. Oalumínio ocorre principalmente na moscovita $\mathrm{KAl}_{2}\left[(\mathrm{OH}, \mathrm{F})_{2} \mathrm{Al}_{2} \mathrm{Si}_{3} \mathrm{O}_{10}\right]$, caulinita $\mathrm{Al}_{4}\left(\mathrm{Si}_{4} \mathrm{O}_{10}\right)(\mathrm{OH})_{8}$, clorita e ilita $\mathrm{K}_{0,9} \mathrm{Al}_{2}\left[(\mathrm{Si}, \mathrm{Al})_{4} \mathrm{O}_{10}\right](\mathrm{OH})_{2}$. O magnésio ocorre na clorita e esmectita $\left[(\mathrm{Al}, \mathrm{Mg})\left(\mathrm{Si}_{4} \mathrm{O}_{10}\right)\left(\mathrm{OH}_{10}\right) \mathrm{H}_{2} \mathrm{O}\right]$ e na dolomita $(\mathrm{Ca}, \mathrm{Mg}) \mathrm{CO}_{3}$.

A concentração de carbono orgânico é maior na fração granulométrica fina. Nesta fração, a concentração variou de 5,27\% a 0,07\% com uma média de concentração de $1,17 \%$ na fração granulométrica fina e $0,58 \%$ na fração granulométrica grossa.

As maiores concentrações do $\mathrm{C}_{\text {org }}$ localizam-se próximos às nascentes dos rios e onde a cobertura arbórea é mais desenvolvida. Esta característica constatada na área de estudo, também foi citada por Laybauer, 1995, em seus estudos. Já os locais com interferência antrópica (e. g.: reflorestamentos) fornecem valores de $\mathrm{C}_{\text {org }}$ mais baixos.

Devido ao fato de minerais,como a goetita, ilita e esmectita e a matéria orgânica serem responsáveis pela retenção ou liberação de grande parte dos metais no ambiente aquático (Forstner, 1989 in Laybauer, 1995), é esperado maiores concentrações de metais na fração granulométrica $<0.088 \mathrm{~mm}$, que também é compatível com as maiores concentrações de $\mathrm{Al}, \mathrm{Mn}$ e Fe na fração granulométrica fina.

Além do enriquecimento de metais pesados na menor fração granulométrica, observou-se também um enriquecimento de oeste para leste, na área do parque e seus arredores, porém sem indicar alguma anormalidade, com exceção do cádmio.

A partir da determinação do fator de contaminação (FC) para a área, obteve-se os maiores valores para o cádmio em locais fora dos limites do parque, que sofreram alguma intervenção, indicada pelos focos erosivos na margem do rio e a observação da elevada turbidez da água.

Na tabela 7 podem ser vistos alguns valores dos limites estabelecidos para metais pesados em sedimentos de corrente e compará-los com as concentrações destes elementos na área de estudo. 
Tabela 7: Limites estabelecidos para os metais pesados e background no caso do níquel em sedimentos de corrente. Valores mínimos,máximos, média e desvio padrão da concentração destes metais na fração granulométrica $<0,088 \mathrm{~mm}$, determinados pelo método $A A S$.

\begin{tabular}{|c|c|c|c|c|c|c|}
\hline Elemento & $\begin{array}{c}\text { L1mite } \\
\text { ppm }\end{array}$ & $\begin{array}{l}\text { Fonte de } \\
\text { Consulta }\end{array}$ & $\begin{array}{c}\text { Valor } \\
\text { Min1mo } \\
\text { (ppm) }\end{array}$ & $\begin{array}{c}\text { Valor } \\
\text { Máx1mo } \\
\langle\text { ppmi }\end{array}$ & $\begin{array}{c}\text { Média } \\
\text { (z) }\end{array}$ & $\begin{array}{c}\text { Desvio } \\
\text { Padrăo } \\
\text { (₹) }\end{array}$ \\
\hline $\mathrm{Cr}$ & 25 & CETESB 1985 & 45,0 & 140,0 & 79,0 & 41,3 \\
\hline $\mathrm{Co}$ & 19 & TUREKIAN 19B1 & 15,0 & $6 \mathrm{~B}, 5$ & 33,3 & 16,0 \\
\hline $\mathrm{N} 1$ & 32 & DNEM 1993 & 54,7 & 143,2 & 82,1 & 35,7 \\
\hline $\mathrm{Cu}$ & 10 & CETESB 1985 & 14,0 & 46,5 & 27,0 & 11,2 \\
\hline $\mathrm{Zn}$ & 20 & CETESB 1985 & 16,0 & 95,5 & 39,8 & 16,7 \\
\hline $\mathrm{Cd}$ & 5 & CETESB 1985 & 5,85 & 11,7 & 8,8 & 2,1 \\
\hline $\mathrm{Pb}$ & 20 & CETESB 1985 & 17,2 & 304,0 & 119,9 & 93,2 \\
\hline
\end{tabular}

Tabela 8: Variações e médias das concentrações dos Metais Pesados, em ppm, nas diferentes frações granulométricas investigadas.

\begin{tabular}{|c|c|c|c|c|}
\hline \multicolumn{2}{|c|}{ Elemento } & \multirow{2}{*}{\begin{tabular}{|l|} 
Fraçio $>0,149 \mathrm{~mm}$ \\
25,17
\end{tabular}} & \multirow{2}{*}{$\begin{array}{l}\text { Fraģåo entre } \\
0,149 \mathrm{~mm}=0,089 \mathrm{~mm} \\
30,0\end{array}$} & \multirow{2}{*}{$\begin{array}{l}0,088 \mathrm{~mm} \\
45,0\end{array}$} \\
\hline $\mathrm{Cr}$ & $\begin{array}{l}\text { Valor } \\
\text { Mínimo }\end{array}$ & & & \\
\hline & \begin{tabular}{|l|} 
Valor \\
Máximo
\end{tabular} & 134,19 & 80,0 & 140,0 \\
\hline & Média & 69,55 & 43,66 & 79,09 \\
\hline & $\begin{array}{l}\text { Desvio } \\
\text { Padrāo }\end{array}$ & 41,34 & 15,04 & 29,32 \\
\hline \multirow[t]{4}{*}{$\mathrm{Co}$} & \begin{tabular}{|l} 
Valor \\
Minimo
\end{tabular} & 14,76 & 14,5 & 15,0 \\
\hline & $\begin{array}{l}\text { Valor } \\
\text { Máximo }\end{array}$ & 68,48 & 55,64 & 68,5 \\
\hline & Média & 37,25 & 28,82 & 33,34 \\
\hline & $\begin{array}{l}\text { Desvio } \\
\text { Padrão }\end{array}$ & 17,77 & $15,3 \mathrm{~B}$ & 16,11 \\
\hline \multirow[t]{4}{*}{$\mathrm{Ni}$} & \begin{tabular}{|l|} 
Valor \\
Mínimo
\end{tabular} & 29,50 & 35,52 & 54,67 \\
\hline & $\begin{array}{l}\text { Valor } \\
\text { Máximo }\end{array}$ & 134,19 & 53,30 & 143,19 \\
\hline & Media & 62,04 & 42,32 & 82,12 \\
\hline & \begin{tabular}{|l|} 
Desvio \\
padrāo
\end{tabular} & 42,70 & 6,41 & 35,68 \\
\hline \multirow[t]{4}{*}{$\mathrm{Cu}$} & $\begin{array}{l}\text { Valor } \\
\text { Mínimo }\end{array}$ & 12,00 & 12,80 & 14,00 \\
\hline & \begin{tabular}{|l|} 
Valor \\
Máximo
\end{tabular} & 46,00 & 38,00 & 46,55 \\
\hline & Média & 28,73 & 21,45 & 27,00 \\
\hline & $\begin{array}{l}\text { Desvio } \\
\text { padräo }\end{array}$ & 13,32 & 9,75 & 11,24 \\
\hline \multirow[t]{4}{*}{$2 \mathrm{n}$} & $\begin{array}{l}\text { Valor } \\
\text { Minimo }\end{array}$ & 5,60 & 7,14 & 15,96 \\
\hline & $\begin{array}{l}\text { Valor } \\
\text { Máximo } \\
\end{array}$ & 108,00 & 75,84 & 95,52 \\
\hline & Mádia & 39,44 & 40,57 & 39,79 \\
\hline & $\begin{array}{l}\text { Desvio } \\
\text { Padrão }\end{array}$ & 34,33 & 26,81 & 16,72 \\
\hline \multirow[t]{4}{*}{$c d$} & $\begin{array}{l}\text { Valor } \\
\text { Mínimo } \\
\end{array}$ & 5,40 & 7,15 & 5,85 \\
\hline & $\begin{array}{l}\text { Valor } \\
\text { Máximo } \\
\end{array}$ & 18,81 & $7, \mathrm{BO}$ & 11,70 \\
\hline & Média & 9,55 & 7,47 & 8,78 \\
\hline & $\begin{array}{l}\text { Desvio } \\
\text { Padräo }\end{array}$ & 4,73 & 0,32 & 2,09 \\
\hline \multirow[t]{4}{*}{$\mathrm{Db}$} & $\begin{array}{l}\text { Valor } \\
\text { Mínimo }\end{array}$ & 22,96 & 17,20 & 17,23 \\
\hline & $\begin{array}{l}\text { Valor } \\
\text { Máximo }\end{array}$ & 189,52 & 280,16 & 304,00 \\
\hline & Media & 63,25 & $84,8 \mathrm{~B}$ & 119,92 \\
\hline & $\begin{array}{l}\text { Desvio } \\
\text { padrao } \\
\end{array}$ & 47,69 & 78,81 & 93,19 \\
\hline \multirow[t]{4}{*}{$\mathrm{Li}$} & $\begin{array}{l}\text { Valor } \\
\text { Mínimo } \\
\end{array}$ & 3,80 & 3,00 & 2,80 \\
\hline & $\begin{array}{l}\text { Valor } \\
\text { Máximo } \\
\end{array}$ & 7,60 & 4,50 & 8,00 \\
\hline & Média & 4,85 & 3,75 & 4,95 \\
\hline & $\begin{array}{l}\text { Desvio } \\
\text { Padrão }\end{array}$ & 1,59 & 0,75 & 2,02 \\
\hline
\end{tabular}


Pela tabela 7 observa-se que todos as médias das concentrações na fração $<0,088 \mathrm{~mm}$ estão acima dos limites e valores estabelecidos para comparação. Porém estes valores de comparação são obtidos em locais provavelmente com características físicas distintas da área de estudo, o que vem a demonstrar a importância de obter valores de referência locais.

\section{CONCLUSÕES}

Os níveis de contaminação dos sedimentos da área em estudo descritos usando o fator de contaminação (FC), demonstraram que o cádmio (1 a 22ppm) é o elemento de concentração mais alta, indicando uma certaanomalia deste elemento em relação a toda a área investigada (tabela 8). Já os outros metais apresentam baixo fator de contaminação (FC), caracterizando a área em estudo com baixa concentração destes metais e têmcomo fonte, as rochas quartzíticas e filitos da formação Cercadinho e do Grupo Itacolomi, além dos clorita-xistos do Grupo Sabará.

A fração argilosa dos sedimentos junto ao material orgânico é a fração principal para os carreadores geoquímicos ativos, tanto de origem natural quanto antrópica e conseqüentemente com a maior concentração de metais pesados (Forstner, 1989 in Laybauer, 1995).Isto se deve à capacidade de troca de cátions, facultada pela grande área específica dos argilominerais, como a clorita, caulinita, ilita, esmectita, ao lado da facilidade de transporte das argilas pelas águas superficiais devido a sua granulometria fina.

Em geral todos os elementos analisados mostram um enriquecimento natural de oeste para leste. Quanto aos metais com valores próximos ao background definido no parque e seus arredores, também é perceptível que suas principais fontes são as rochas descritas anteriormente.

Este trabalho estabelece parâmetros que podem ser utilizados para estudos posteriores, uma vez que esta área pode ser considerada relativamente livre de intervenções antrópicas atuais, com exceção do $\mathrm{Cd}$, o qual apresentou valores anômalos, sem contudo indicar, uma origem antrópica.

Assim as concentrações dos metais desta área podem ser usadas como base para outras pesquisas da região, indicando uma situação adequada para os ecossistemas aquáticos da área investigada e sem problemas ambientais graves, com exceção para o $\mathrm{Cd}$, o qual necessita uma melhor investigação sobre a sua origem.

\section{AGRADECIMENTOS}

Agradecemos o apoio logístico e financeiro da UFOP-Degeo e DEMIN, da UFMG-IGC-CPMTC, da FUNED, do CNPq e da FAPEMIG e a colaboração dos funcionários e professores involvidos.

\section{REFERÊNCIAS}

Alloway,B. J., 1993. Heavy Metals in soils. Blackie, Glasgow and London. 339p;

APHA, American Public Health Association, 1992. Standard Methods for Examination Publishing Company. 144p;

Baltazar, O F.;Raposo, F. O \& Mattos, D. M. M. de., 1993. Estratigrafia, Petrografia e Petrologia. In Programas de Levantamentos Básicos do Brasil. PLGB. Mapeamento Geológico da Folha Mariana SF.23-x-B-I. Belo Horizonte. Texto Explicativo, cap. 02, p. 17-93;

CETESB, 1988. Guia de Coleta e Preservação de Amostras de Água. 1 edição. São Paulo. 149p;

DNPM, 1993. Programa de Levantamentos Geológicos Básicos do Brasil. Folha SF.23-x-B-I, Mariana. Brasília.

Eleutério, L., 1997. Diagnóstico da Situação Ambiental da Cabeceira na Bacia do Rio Doce, M.G., no âmbito das contaminações por metais pesados em sedimentos de fundo. Dissertação de Mestrado, Curso de Pós-graduação em Geociências da UFOP, Ouro Preto, M.G. 154p.

Klaassen, C. D., Amdur, M. O \& Doull, J., 1996. Toxicology. MacGraw-Hill. New York, Bogotá, Caracas, Lisbon, London, Madrid, México City, Milan, Sidney, Tokyo, Toronto. P.691736 ;

Laybauer, L., 1995. Análise de Transferência de Metais Pesados em Águas e Sedimentos Fluviais na Região das Minas de Camaquã, R.S.- Dissertação de Mestrado, Curso de Pósgraduação em Geociências da UFRGS, Porto Alegre, R. S. $164 \mathrm{p}$

Leco, Corporation Form., 1995. Instruction Manaul- Sc 444 Dr Sulfur and Carbon Analyzers- Version 3.0- No 200-504;

Roeser, H., Polli, G. O; Krisotakis, K., 1984. Prospequição Geoquímica no Embasamento SE do Quadrilátero Ferrífero, Minas Gerais (Folha de Ponte Nova). In: Anais do XXXIII Congresso Brasileiro de Geologia, Rio de Janeiro. P. 45524560;

Teixeira, W., 1985. A Evolução Geotectônica da Porção Meridional do Cráton do São Francisco, com Base em Interações Geocronológicas. Tese de Doutorado, IG-USP. 